\title{
Development and validation of UV chromatographic method for quantification of Copper and Copper nanoparticles in different matrices and pharmaceutical products
}

\author{
Mai A Fadel ${ }^{\text {Corresp., } 1}{ }^{\text {, Dalia M.A. Elmasry }}{ }^{2}$, Farida H Mohamed ${ }^{3}$, Asmaa M Badawy $^{3}$, Hanaa A Elsamadony ${ }^{4}$ \\ 1 Pharmacology and pyrogen unit, Department of chemistry, toxicology and feed deficiency, Animal Health Research Institute, Agriculture Research \\ Center, Giza, Egypt \\ 2 Nanomaterials research and synthesis unit, Reference Laboratory for Veterinary Quality Control on Poultry Production, Animal Health Research Institute, \\ Agriculture Research Center, Giza, Egypt \\ 3 Department of Immunology Research, Animal Health Research Institute, Agriculture Research Center, Giza, Egypt \\ 4 Department of Poultry disease and Research, Animal Health Research Institute, Agriculture Research Center, Giza, Egypt \\ Corresponding Author: Mai A Fadel \\ Email address: dr.mai87@yahoo.com
}

Background. The applications of $\mathrm{Cu}$ and CuNPs based on the earth-abundant and inexpensive Cu metal have generated a great deal of interest in recent years, including medical applications. A novel, specific, precise, accurate and sensitive reverse-phase highperformance liquid chromatography (RP-HPLC) method with UV detection has been developed and validated to quantify copper (Cu) and copper nanoparticles (CuNPs) in different biological matrices and pharmaceutical products. Methods. The developed method has been validated for linearity, precision, sensitivity, specificity and accuracy. Cu concentration was detected in pharmaceutical products without an extraction process. Moreover, liver, serum and muscle tissues were used as biological matrices. High $\mathrm{Cu}$ recovery in biological samples was afforded by using citric acid as a green chelating agent, exact extraction time and $\mathrm{pH}$ adjustment. Cu pharmaceutical and biological samples were eluted by acetonitrile: ammonium acetate $(50 \mathrm{mM})$ with $0.5 \mathrm{mg} / \mathrm{ml}$ EDTA (30:70 v: v) as an isocratic mobile phase. EDTA reacted with $\mathrm{Cu}$ ions forming a Cu-EDTA coloured complex, separated through the $\mathrm{C} 18$ column and detected by UV at $310 \mathrm{~nm}$. Results. The developed method was specific with a short retention time of $4.95 \mathrm{~min}$. It achieved high recovery from $100.3 \%$ - $109.9 \%$ in pharmaceutical samples and $96.8 \%-105.7 \%$ in biological samples. The precision RSD percentage was less than two. The method was sensitive by achieving low detection limits (DL) and quantification limits (QL). Conclusion. The validated method was efficient and economical for detecting $\mathrm{Cu}$ and CuNPs by readily available chemicals as EDTA and Citric acid with C18 column, which present the best results on RP- HPLC. 
1 Title: Development and Validation of UV Chromatographic Method for Quantification of Copper

2 and Copper nanoparticles in Different Matrices and Pharmaceutical Products

3 Authors: Mai A Fadel ${ }^{1}$, Dalia M.A. Elmasry², Farida H. Mohamed ${ }^{3}$, Asmaa. M. Badawy ${ }^{3}$, and

4 Hanaa A Elsamadony ${ }^{4}$

5 Affiliation: ${ }^{1}$ Pharmacology and pyrogen unit, Department of chemistry, toxicology and feed

6 deficiency, Animal Health Research Institute, Agriculture Research Center, Giza, Egypt.

$7 \quad$ Nanomaterials research and synthesis unit, Reference Laboratory for Veterinary Quality Control

8 on Poultry Production, Animal Health Research Institute, Agriculture Research Center Giza,

9 Egypt. Orchid no.: 0000-0002-9188-4520, ${ }^{3}$ Department of Immunology Research, Animal Health

10 Research Institute, Agriculture Research Center, Giza, Egypt. Farida H. Mohamed (Orchid

11 no.:0000-0002-6357-5085). Asmaa. M. Badawy (Orchid no.: 0000-0003-1613-214X), ${ }^{4}$

12 Department of Poultry disease and Research, Animal Health Research Institute, Agriculture

13 Research Center, Giza, Egypt. Orchid no.: 0000-0002-9770-9854

14 Corresponding Author: Mai A Fadel; Pharmacology and pyrogen unit, Department of chemistry, toxicology and feed deficiency, Animal Health Research Institute, Agriculture Research Center,

16 Giza, Egypt. Orchid no. 0000-0002-8440-439X, Postal code: 264; Tel: +20 01013059529; Email

17 Address: dr.mai87@yahoo.com 


\section{Abstract}

Background. The applications of copper $(\mathrm{Cu})$ and copper nanoparticles $(\mathrm{CuNPs})$ based on the earth-abundant and inexpensive $\mathrm{Cu}$ metal have generated a great deal of interest in recent years, including medical applications. A novel, specific, precise, accurate, and sensitive reverse-phase high-performance liquid chromatography (RP-HPLC) method with UV detection has been developed and validated to quantify $\mathrm{Cu}$ and $\mathrm{CuNPs}$ in different biological matrices and pharmaceutical products.

Methods. The developed method has been validated for linearity, precision, sensitivity, specificity, and accuracy. $\mathrm{Cu}$ concentration was detected in pharmaceutical products without an extraction process. Moreover, liver, serum, and muscle tissues were used as biological matrices. High $\mathrm{Cu}$ recovery in biological samples was afforded by using citric acid as a green chelating agent, exact extraction time and $\mathrm{pH}$ adjustment. $\mathrm{Cu}$ pharmaceutical and biological samples were eluted by acetonitrile: ammonium acetate $(50 \mathrm{mM})$ with $0.5 \mathrm{mg} / \mathrm{ml}$ EDTA $(30: 70 \mathrm{v}: \mathrm{v})$ as an isocratic mobile phase. EDTA reacted with $\mathrm{Cu}$ ions forming a $\mathrm{Cu}$-EDTA coloured complex, separated through the C18 column and detected by UV at $310 \mathrm{~nm}$.

Results. The developed method was specific with a short retention time of 4.95 minutes. It achieved high recovery from $100.3 \%$ to $109.9 \%$ in pharmaceutical samples and from $96.8 \%$ to $105.7 \%$ in biological samples. The precision RSD percentage was less than two. The method was sensitive by achieving low detection limits (DL) and quantification limits (QL).

Conclusion. The validated method was efficient and economical for detecting $\mathrm{Cu}$ and CuNPs by readily available chemicals as EDTA and citric acid with C18 column, which present the best results on RP-HPLC. 
40 Keywords: Copper nanoparticles, RP-HPLC, biological matrices, pharmaceutical products, and

41 UV chromatography.

42

43

44

\section{Introduction}

Copper $(\mathrm{Cu})$ is an essential micronutrient due to its vital role in the body's biological and biochemical processes. It is found in all body tissues and plays a role in making red blood cells and maintaining nerve cells and the immune system (Soetan et al., 2010). However, $\mathrm{Cu}$ is very toxic in excessive doses and leads to some metabolic disorders and more tissue accumulation and damage (Chen et al., 2021 and Ognik et al., 2016). In recent years, copper nanoparticles (CuNPs) have had a strong focus on health-related processes since they possess antibacterial properties and antifungal activity besides their catalytic, optical, and electrical properties (Argueta-Figueroa et al., 2014). The development of these CuNPs is constantly growing and progressing for future technologies (Camacho-Flores et al., 2015).

Recently, some studies declared the effect of nanoparticles in their metallic form as CuNPs to be antiviral (Tomaszewski et al., 2017). Nanometric-sized particles are also efficient in drug delivery, ionizing agents and diagnostic imaging. Additionally, a rapid increase in the improper usage of medications such as antibiotics has led the medical field to investigate new alternatives of biocides against infectious diseases (Patra et al., 2018). The emergence of the CuNPs analysis lies in the growing area of applications, and it enhances the knowledge of this new material's nature (Khan et al., 2019).

Nano-metals can penetrate biological membranes due to their high physiological solubility and physicochemical properties (Awaad et al., 2021). Thus, the data declared by Escalona et al. (2017) proved that CuNPs had higher plasma ceruloplasmin activity than cupper sulfide (CuS). In 
62 addition, much excretion of $\mathrm{CuS}$ than that of $\mathrm{CuNPs}$ confirmed that $\mathrm{Cu}$ administered as $\mathrm{CuNPs}$

63 was better dissolved than $\mathrm{CuS}$ in an acidic environment and probably better absorbed in the

64 digestive tract (Cholewińska et al.,2018).

65 There are several methods for the characterization of CuNPs. One of the standard methods to 66 analyze the shape and size of the CuNPs is the Transmission Electron Microscopy (TEM). Several 67 other methods, such as Dynamic Light Scattering (DLS) and X-Ray Scattering at Small Angles 68 (SAXS), are also used to measure the particle size. Besides this, only the TEM analysis gives authentic images of the morphology and the shape of the nanostructures. The inorganic material's morphological information is collected using an instrument known as the Scanning Electron

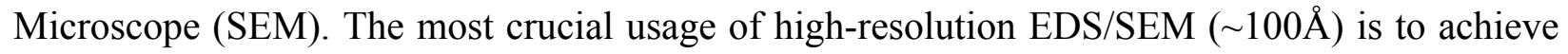
three-dimensional images with large depth fields using a simple sample preparation (Choudhary et al., 2019).

Copper colloids and all other metals are usually absorbed in the ultraviolet-visible (UV-Vis) range because of the excitation of surface plasmon resonance (SPR). However, UV-Vis spectroscopy is considered to be a convenient method to characterize CuNPs. On the macroscopic scale, some of

77 the colloidal metal materials are comparably different, and in the visible region, some give distinct absorption peaks. The metals such as copper, silver, and gold have shown prominent absorption peaks (Moniri et al., 2017). Meanwhile, these methods cannot quantify $\mathrm{Cu}$ concentration either in its original or nano form in different pharmaceutical products and biological matrices. atomic absorption spectrometry (AAS) (Wang et al., 2014), inductively coupled plasma mass spectrometry (ICP-MS) (Cao et al., 2020), ion-pair HPLC (Shen et al., 2006), and colorimetric 
85

diverse analytes types, from small organic molecules and ions to large biomolecules and polymers with highly reproducibility, sensitivity, specificity, precision and robustness (Dong, 2013). Although UV-Vis detectors are the most common type of detectors used for HPLC because of their relative ease-of-use and high sensitivity, it is not applicable for $\mathrm{Cu}$ concentration detection. This study presents a method a novel insight into the quantification of $\mathrm{Cu}$ and $\mathrm{CuNPs}$ in biological matrices and pharmaceutical products by the development and validation of the UVHPLC method.

\section{Materials and Methods}

\subsection{Detection Theory}

$4 \mathrm{Cu}$ ions cannot be detected by the UV detector for RP-HPLC by the ordinary extraction method. This study depends on the reaction between $\mathrm{Cu}$ ions and EDTA to form a stable complex. EDTA is a strong chelating agent. It can form very stable complexes with the transition elements due to EDTA has hexadentate ligand (Al-Qahtani,2017).

This concept was nearly similar to that in the studies by Khuhawar and Lanjwani (1995) and Rasul Fallahi and Khayatian (2017), who used colored reagents to detect metal ions. This Cu-EDTA complex (Figure 1) is easily detected by the UV detector at $310 \mathrm{~nm}$.

\subsection{Standards, Drugs, and Chemicals:}

Copper nitrate $\left(\mathrm{Cu}\left(\mathrm{NO}_{3}\right)_{2}\right)$ standard in $\mathrm{HNO}_{3}(0.5 \mathrm{~mol} / \mathrm{L}) 1000 \mathrm{mg} / \mathrm{L}$ was purchased from Merck. Acetonitrile (ACN) and methanol $(\mathrm{MeOH})$ were of HPLC grade (Fischer). Ammonium acetate was purchased from Riedel-de Haen (Buchs, SG, Switzerland). Ethylenediaminetetraacetic acid (ETDA) was from Oxford Lab Chem, India. The analytical grade chemicals and reagents were supplied from BDH Laboratories Supplies (BDH Chemical Ltd., Poole, U.K.). The used 
107 pharmaceutical products to check the applicability of the method were Clo-Fix $(25 \mathrm{gm} / \mathrm{L})$ by

108 Cardimyer pharmaceutical industries (Al Buhayrah, Egypt) and Meracid (10mg/L) by EVP Co.

109 (Alexandria, Egypt). The CuNPs product was supplied as copper-chitosan nanocomposite

110 (CuCNPs) from the Nanotechnology Research and Synthesis Unit, Animal Health Research

111 Institute (AHRI), Egypt. Copper nanoparticles in extracted matrices were characterized by

112 Transmission electron microscope (TEM) in Central lab., National Research Center (NRC),

113 Egypt. Copper nanoparticles were with an average size 24.71 $\pm 1.68 \mathrm{~nm}$ Figure (2).

\section{2.3. Instrumentation:}

2.3.1. HPLC System: Agilent Series 1200 quaternary gradient pump, Series 1200 autosampler,

Series 1200 UV-Vis detector, and HPLC 2D ChemStation software (Hewlett-Packard, Les Ulis,

117 France). Agilent C18 column (4.6mm id, $150 \mathrm{~mm}, 5 \mu \mathrm{m}$ particle size).

2.3.2. Inductively coupled plasma mass spectrometry (ICP-MS): Thermo ICP-MS model iCAPRQ.

\subsection{Sample Preparation}

\subsubsection{Pharmaceutical Samples:}

Drug samples were prepared by taking an accurate drug volume in $1 \%$ nitric acid to have a final concentration $(1 \mathrm{mg} / \mathrm{mL})$. The mobile phase diluted variable concentrations.

\subsubsection{Biological Matrices Extraction}

Liver and muscle (blank) tissues were obtained from SPF chicken aged 28 days. These chickens were supplied from QRD experimental farm for research and scientific service, Giza, Egypt. It is 
128 Middle East, Cairo, Egypt. The slaughtered chickens were transported in an icebox to be prepared

129 for blank and spiked samples in the laboratory. Tissues were grounded and homogenized and kept

130 at $-70^{\circ} \mathrm{C}$ until the analysis started. Two grams of tissue samples were weighed. The extraction

131 procedures started with $2 \mathrm{ml} 10 \mathrm{mM}$ citric acid with an adjusted $\mathrm{pH}$ at 2.3 by $10 \%$ sodium hydroxide

$132(\mathrm{NaOH})$ and $2 \mathrm{ml}$ methanolic ammonium acetate $(50 \mathrm{mM})$ with $0.5 \mathrm{mg} / \mathrm{ml}$ EDTA. The mixture was

133 vortexed thoroughly for two minutes. They were then shaken for two hours at 200rpm at room

134 temperature. Two millilitres of chloroform were also added and mixed well. The samples were

135 centrifuged at $3000 \mathrm{rpm}$ for ten minutes. The organic phase was separated, and another $2 \mathrm{ml}$ of

136 chloroform was added for repetition of the extraction. The extract $(4 \mathrm{ml})$ was evaporated, and the

137 residues were dissolved in the $1 \mathrm{ml}$ mobile phase. The sample $(20 \mu 1)$ was injected onto the HPLC

138 column.

139 The same procedures were adopted in the serum sample extraction. The difference was in the 140 sample volume $(0.5 \mathrm{~mL}$ serum $)$ with equal volumes of the other extracted chemicals. Also, the 141 evaporated sample was reconstituted with a $250 \mu 1$ mobile phase.

2.5. Chromatographic Conditions (SIELC Technologies):

143 The elution mixture consisted of ACN: ammonium acetate $(50 \mathrm{mM})$ with $0.5 \mathrm{mg} / \mathrm{ml}$ EDTA $(30: 70$ $144 \mathrm{v}: \mathrm{v})$ as an isocratic mobile phase. The flow rate was $1 \mathrm{ml} / \mathrm{min}$ with UV wavelength detection at $145310 \mathrm{~nm}$. The stop time was eight minutes with a post time of one minute.

\subsection{Standard Preparation and Calibration Curve:}

147 The copper stock standard solution was prepared at a $1 \mathrm{mg} / \mathrm{mL}$ concentration in $1 \%$ nitric acid and 148 diluted to prepare fortified solution at a $100 \mu \mathrm{g} / \mathrm{ml}$ concentration. Calibration standards were 149 prepared at various concentrations $(0.05,0.1,0.2,0.4,0.8,1,5,10,15$, and $20 \mu \mathrm{g} / \mathrm{ml})$ from the 
150 fortified solution by diluting with $1 \%$ nitric acid to ascertain the actual concentration of $\mathrm{Cu}$ in

151 pharmaceutical products and $\mathrm{Cu}$ - nanoparticles preparation ( $\mathrm{CuNPs})$.

152 The calibration curve of biological matrices was prepared by spiking blank samples (serum, liver,

153 and muscle) with various fortified solution concentrations to have calibration samples $(0.1,0.2$,

$1540.4,0.8,1,5,10$, and $15 \mu \mathrm{g} / \mathrm{g})$.

155 Quality control samples for pharmaceutical products and nanocomposite were 10 and $1 \mu \mathrm{g} / \mathrm{mL}$, 156 respectively. Accuracy was determined by the standard addition of $50 \mathrm{ng} / \mathrm{mL}$ on three 157 pharmaceutical products levels at 5,10 , and $15 \mu \mathrm{g} / \mathrm{mL}$ and $0.5,1$, and $1.5 \mu \mathrm{g} / \mathrm{mL}$ nanocomposite.

158 Quality control serum samples were prepared at three different concentrations 0.8, 1.6, and $1592.4 \mu \mathrm{g} / \mathrm{mL}$. Moreover, liver quality control levels were at 1,2 , and $3.5 \mu \mathrm{g} / \mathrm{g}$ and muscle samples at $1600.2,0.4$, and $0.6 \mu \mathrm{g} / \mathrm{g}$.

\subsection{Method Validation:}

162 This was accomplished in concrete terms according to ICH,2005 and USP,2019 as specificity, 163 linearity, and range, precision, recovery, and accuracy, detection limit (DL) and quantification $164 \operatorname{limit}(\mathrm{QL})$, and robustness and system suitability test (SST).

\subsection{Statistical Evaluation}

The obtained results were analyzed using SPSS Inc., version 22.0, Chicago, IL, the USA to

167 calculate the mean, standard deviation (SD) and the relative standard deviation (RSD) (Morgan et 168 al., 2019).

\section{3. Results}

\subsection{High-Performance Liquid Chromatograph (HPLC):}




\subsubsection{Method Validation:}

172 1. Linearity, range, precision, accuracy, DL, and QL were illustrated in Table (1).

173 Linearity and range: The linearity of $\mathrm{Cu}$ and $\mathrm{CuNPs}$ was evaluated by the calibration curve on a

174 range of eight concentrations. The correlation coefficient (R) ranged from 0.9995 to 0.9999.

175 Precision: The precision of a method is the degree of agreement among individual test results

176 when the procedure is applied repeatedly to multiple samplings. It is carried out on intra-day and

177 inter-day precisions. It is expressed as the relative standard deviation (coefficient of variance, CV)

178 of a series of measurements. Intra-day precision was performed on six replicates of the analyte on

179 the same day. Inter-day precision was performed on different days and by different analyzers.

180 Intra- and inter-day precisions RSD percentage in dosage form were evaluated and found to be

1810.696 and 1.04, respectively. In biological samples, intra-day precision RSD percentage ranged

182 from $0.52 \%$ to $0.6 \%$, while the inter-day precision range was from $0.85 \%$ to $1.36 \%$.

183 Accuracy (standard addition): The accuracy of an analytical method is the degree of agreement

184 of test results generated by the actual value. The accuracy must be done on three levels: $50 \%$, $185100 \%$, and $150 \%$.

186 Sensitivity: The sensitivity was determined by detection limit (DL) and quantification limit (QL).

187 DL is defined as the lowest concentration at which the instrument can detect but not quantify, and 188 the noise to signal ratio for DL should be 1:3. QL is defined as the lowest concentration at which 189 the instrument can detect and quantify. The noise to signal ratio for LOQ should be 1:10 (Rao, 1902018 and Uddin et al.,2008).

191

192

193
2. Robustness: It was performed by slight changes of the mobile phase composition, the wavelength of UV, and column temperature, which did not lead to any essential changes in the chromatographic system's performance as specificity and system 
194

195

196

197

198

199

200

201

202

203

204

205

206

207

208

209

210

211

212

213

214

215

suitability parameters. The method was robust by calculating pooled RSD percentage for all shifts at a certain concentration level $(1 \mu \mathrm{g} / \mathrm{mL})$, as shown in Table 1 . The acceptance criterion of the pooled RSD percentage is $\leq 6 \%$.

3. Specificity: The specificity demonstrated with chromatogram through short, specific retention time (4.955 minutes), as there was no impurities interference between the extracted samples and pure standard (Figure 3).

\subsubsection{System Suitability Test (SST):}

The method showed to be suitably performed under the optimized conditions, and the RSD percentage was found to be less than $1 \%$ for system suitability parameters in Table 2.

\subsubsection{Application of Pharmaceutical Products:}

The method developed here was applied to various concentrations $(5,10$, and $15 \mu \mathrm{g} / \mathrm{mL})$ of solutions made from pharmaceutical products for determining the content of $\mathrm{Cu}$ and $\mathrm{CuNPs}(0.5$, $1,1.5 \mu \mathrm{g} / \mathrm{mL})$. The values of the overall drug percentage recoveries and the RSD value of $\mathrm{Cu}$ are $100.3-101.1 \%$ and $0.01-0.2 \%$, respectively, and were $103.4-109.9 \%$ and $0.1-1.1 \%$ for CuNPs as presented in Table 3, indicating that these values are acceptable and the method is accurate and precise. Furthermore, there was no interference and no degradation products. High specificity of this method was confirmed by absence of interference from the sample excipients at the detection wavelength.

\subsection{Inductively coupled plasma mass spectrometry (ICP-MS):}

Biological samples and pharmaceutical products were analyzed for copper detection by ICP-MS (Varian 810/820-MS ICP Mass Spectrometer) to ensure results of HPLC. Results illustrated in table (4).

Peer] An. Chem. reviewing PDF | (ACHEM-2021:08:65001:1:2:NEW 15 Jan 2022) 


\section{Discussion}

217 Copper $(\mathrm{Cu})$ is an essential trace element but causes toxic effects with high doses. In this study,

$218 \mathrm{Cu}$ and CuNPs were detected by a precise, accurate, and selective UV RP-HPLC method in dosage

219 form and different matrices (serum, liver, and muscles). $\mathrm{Cu}$ detection in pharmaceutical products

220 was done without extraction procedures. It is an economical method as fewer solvents and rapid

221 detection are used. This is unlike the findings by Takele et al. (2017), who detected bromazepam-

222 copper (II) complex through an extraction process. The developed method for $\mathrm{Cu}$ detection in

223 biological matrices was validated after some modifications in the original one (Khuhawar and

224 Lanjwani, 1995). Copper is one of the heavy metals that requires potent chelating agents like citric

225 acid and EDTA to be extracted and detected (Jafri et al., 2017). Green chelating agents are readily

226 biodegradable and safer chemicals with less phytotoxicity (Chauhan et al., 2015). In this study,

227 citric acid was used as a green chelating agent for the recovery of copper, which is in accordance

228 with the study by Asemave (2018), who estimated its recovery by $88 \%$. Besides, $\mathrm{pH}$ adjustment

229 and time of extraction give higher recovery. Herein, citric acid is a natural organic acid, and the

230 green chelating agents afford safe and powerful extraction and support the concept of sustainable

231 chemistry (Gómez-Garrido et al., 2018).

232 The mixing of the extraction solvent to have EDTA, ammonium acetate, and citric acid gave the

233 best chelating power for the purification of $\mathrm{Cu}(\mathrm{Hu}$ et al., 2013). On keeping this line, EDTA is

234 the most widely used acid in modified forms in extracting cationic micronutrients as $\mathrm{Cu}^{1+}$. Copper

235 is an electron donor in its oxidative state $\left(\mathrm{Cu}^{1+}\right.$ and $\left.\mathrm{Cu}^{2+}\right)$ in enzyme synthesis and cofactor in

236 ceruloplasmin for iron hemostasis (Wolf et al., 2015). The solvent mixture chelated $\mathrm{Cu}$ and formed

237 a complex soluble in aqueous-methanolic solution and double extracted by chloroform to be easily 
238 transferred from the aqueous phase to the organic one. Chloroform (organic phase) was evaporated

239 to get very stable hexadentate ligand complex, and the mobile phase eluted this complex. The

240 mobile phase had EDTA as the visualizing agent of $\mathrm{Cu}$ in the $\mathrm{Cu}$-EDTA coloured complex. This

241 coloured complex is a stable chelate and is detected by UV (Pati et al., 2019). This method is

242 selective to $\mathrm{Cu}$ cations rather than the other cations that do not form coloured complexes with

243 EDTA. Cu-EDTA complex was detected through the $\mathrm{C} 18$ column, which gave the best results on

244 reverse-phase HPLC.

245 The developed method is more economical, and there are less health and environmental hazards.

246 This is because of using easily applicable chemicals with RP-HPLC, which is the most

247 conventional chromatography technique. This is in line with the theory of green analytical

248 chemistry, which is part of the concept of sustainable development (Płotka-Wasylka et al., 2021).

249 Also, minimize analytical equipment and shorten the time elapsed between conducting analysis 250 and obtaining reliable analyses (Turner, 2013).

\section{5. Conclusion}

252 This advanced RP-HPLC method has been validated for accuracy, precision, linearity, and

253 reproducibility following ICH and USP guidelines. The limits of detection and quantification are

254 very low for both pharmaceutical products and biological matrices. This is indicated high

255 sensitivity. RP HPLC is used to quantify copper and $\mathrm{Cu}$ NPs via potent chelating agents as citric

256 acid and EDTA for its extraction and detection. Cu-EDTA complex was successfully detected by

257 UV with high selectivity to $\mathrm{Cu}$ cations. $\mathrm{Cu}$-EDTA complex was separated by $\mathrm{C} 18$ column, which

258 gave the best results on reversed-phase HPLC. The method is novel, simple, sensitive, selective,

259 precise, and accurate analytically for $\mathrm{Cu}$ and $\mathrm{CuNPs}$ quantification. 


\section{Author contributions}

261

262

263

264

265

Mai A Fadel: She designed and performed the experiment, statistically analyzed HPLC validation data, and wrote the main draft. Dalia M.A. Elmasry: She prepared Cu-chitosan nanocomposite and performed the experiment. Farida H. Mohamed, Asmaa. M. Badawy, and Hanaa A Elsamadony: They performed the experiment. All authors wrote and revised the full manuscript.

\section{Funding}

This research did not receive any specific grant from funding agencies in the public, commercial, or not-for-profit sectors.

\section{Conflict of interest}

The authors declare that they have no conflict of interest.

\section{Acknowledgements}

Sincere gratitude and profound thanks to the staff of the Department of Chemistry at the Animal Health Research Institute for their support and cooperation in completing this study.

\section{References}

1. Al-Qahtani K. M. A. 2017. Extraction Heavy Metals from Contaminated, Water Using Chelating Agents. Orient J Chem;33(4).

2. Asemave, K. (2018). Greener Chelators for Recovery of Metals and Other Applications. Org. Med. Chem. Int. J, 6, 555694

3. Awaad, M. H., Moustafa, K.-Elk. M. E. L., Zoulfakar, S. A., Elhalawany, M. S., Mohammed, F. F., El-Refay, R. M., \& Morsy, E. A. (2021). The Role of Silver Nanoparticles in The Reluctance of Colisepticemia In Broiler Chickens. Journal of Applied Poultry Research, 100155. 
4. Argueta-Figueroa, L., Morales-Luckie, R. A., Scougall-Vilchis, R. J., \& Olea-Mejía, O. F. (2014). Synthesis, characterization and antibacterial activity of copper, nickel and bimetallic $\mathrm{Cu}-\mathrm{Ni}$ nanoparticles for potential use in dental materials. Progress in Natural Science: Materials International, 24(4), 321-328.

5. Camacho-Flores, B. A., Martínez-Álvarez, O., Arenas-Arrocena, M. C., Garcia-Contreras, R., Argueta-Figueroa, L., de la Fuente-Hernández, J., \& Acosta-Torres, L. S. (2015). Copper: Synthesis Techniques in Nanoscale and Powerful Application as an Antimicrobial Agent. Journal of Nanomaterials, 2015, 415238. https://doi.org/10.1155/2015/415238.

6. Cholewińska, E., Ognik, K., Fotschki, B., Zduńczyk, Z., \& Juśkiewicz, J. (2018). Comparison of the effect of dietary copper nanoparticles and one copper (II) salt on the copper biodistribution and gastrointestinal and hepatic morphology and function in a rat model. PLoS One, 13(5), e0197083.

7. Choudhary, R. C., Kumari, S., Kumaraswamy, R. V., Pal, A., Raliya, R., Biswas, P., \& Saharan, V. (2019). Characterization Methods for Chitosan-Based Nanomaterials. In-Plant Nanobionics (pp. 103-116). Springer, Cham

8. Chen, J., Lan, C., An, H., Jin, Y., Li, Q., Ge, S., Yu, Y., Shen, G., Pan, B., \& Xu, Y. (2021). Potential interference on the lipid metabolisms by serum copper in a women population: A repeated measurement study. Science of The Total Environment, 760, 143375.

9. Cao, Y., Feng, J., Tang, L., Yu, C., Mo, G., \& Deng, B. (2020). A highly efficient introduction system for single cell-ICP-MS and its application to detect copper in single human red blood cells. Talanta, 206, 120174.

10. Chauhan, G., Pant, K. K., \& Nigam, K. D. P. (2015). Chelation technology: a promising green approach for resource management and waste minimization. Environmental Science: 
Processes \& Impacts, 17(1), 12-40.

306

307

308

309

310

311

312

313

314

315

316

317

318

319

320

321

322

323

324

325

326

327
11. Dong, M. (2013). The essence of modern HPLC: advantages, limitations, fundamentals, and opportunities. LCGC North America, 31 (6), 472-479.

12. Escalona, H. E., Zwick, A., Li, H.-S., Li, J., Wang, X., Pang, H., Hartley, D., Jermiin, L. S., Nedvěd, O., \& Misof, B. (2017). Molecular phylogeny reveals food plasticity in the evolution of true ladybird beetles (Coleoptera: Coccinellidae: Coccinellini). BMC Evolutionary Biology, 17(1), 1-11.

13. Esfandiari, N. (2015). Production of micro and nanoparticles of pharmaceutical by supercritical carbon dioxide. The Journal of Supercritical Fluids, 100, 129-141. https://doi.org/https://doi.org/10.1016/j.supflu.2014.12.028

14. Ghaferi, M., Koohi Moftakhari Esfahani, M., Raza, A., Al Harthi, S., Ebrahimi Shahmabadi, H., \& Alavi, S. E. (2021). Mesoporous silica nanoparticles: synthesis methods and their therapeutic use-recent advances. Journal of Drug Targeting, 29(2), 131154.

15. Gibney, S., Hicks, J. M., Robinson, A., Jain, A., Sanjuan-Alberte, P., \& Rawson, F. J. (n.d.). Toward nano bioelectronic medicine: Unlocking new applications using nanotechnology. Wiley Interdisciplinary Reviews: Nanomedicine and Nanobiotechnology, e1693.

16. Gómez-Garrido, M., Mora Navarro, J., Murcia Navarro, F. J., \& Faz Cano, Á. (2018). The chelating effect of citric acid, oxalic acid, amino acids and Pseudomonas fluorescens bacteria on phytoremediation of $\mathrm{Cu}, \mathrm{Zn}$, and $\mathrm{Cr}$ from soil using Suaeda vera. International journal of phytoremediation, 20(10), 1033-1042.

17. Ge, C., Luo, Q., Wang, D., Zhao, S., Liang, X., Yu, L., ... \& Zeng, L. (2014). Colourimetric 
detection of copper (II) ion using click chemistry and hemin/G-quadruplex horseradish peroxidase-mimicking DNAzyme. Analytical Chemistry, 86(13), 6387-6392.

18. Hu, B., He, M., Chen, B., \& Xia, L. (2013). Liquid phase microextraction for the analysis of trace elements and their speciation. Spectrochimica Acta Part B: Atomic Spectroscopy, $86,14-30$.

19. ICH (International Conference on Harmonisation of Technical Requirements for Registration of Pharmaceutical for Human Use) (2005). Validation of Analytical Procedures: Text and Methodology Q2 (R1).

20. Jafri, M. A., Al-Qahtani, M. H., \& Shay, J. W. (2017). Role of miRNAs in human cancer metastasis: Implications for therapeutic intervention. Seminars in Cancer Biology, 44, 117-131.

21. Kasozi, K. I., Otim, E. O., Ekou, J., Matama, K., Zirintunda, G., Ayikobua, E. T., Tamale, A., Mujinya, R., Baty, R. S., \& Albrakati, A. (2021). Multivariate analysis of heavy metals content of beef from Soroti, Uganda.

22. Khuhawar, M. Y., \& Lanjwani, S. N. (1995). High-performance liquid chromatographic determination of uranium using solvent extraction and bis (salicylaldehyde) tetramethylethylenediamine as a complexing reagent. Talanta, 42(12), 1925-1929.

23. Morgan, M. A., Griffith, C. M., Volz, D. C., \& Larive, C. K. (2019). TDCIPP exposure affects Artemia franciscana growth and osmoregulation. Science of The Total Environment, $694,133486$.

24. Moniri, S., Ghoranneviss, M., Hantehzadeh, M. R., \& Asadabad, M. A. (2017). Synthesis and optical characterization of copper nanoparticles prepared by laser ablation. Bulletin of Materials Science, 40(1), 37-43. 
351

352

353

354

355

356

357

358

359

360

361

362

363

364

365

366

367

368

369

370

371

372

373

25. Ognik, K., Cholewińska, E., Czech, A., Kozłowski, K., Nowakowicz-Dębek, B., Szlązak, R., \& Tutaj, K. (2016). Effect of silver nanoparticles on the immune, redox, and lipid status of chicken blood. Czech Journal of Animal Science, 61(10), 450-461.

26. Pati, K., Zhang, F., \& Batley, J. (2019). First report of genome size and ploidy of the underutilized leguminous tuber crop Yam Bean (Pachyrhizus erosus and P. tuberous) by flow cytometry. Plant Genetic Resources, 17(5), 456-459.

27. Patra, J. K., Das, G., Fraceto, L. F., Campos, E. V. R., del Pilar Rodriguez-Torres, M., Acosta-Torres, L. S., \& Shin, H. S. (2018). Nano based drug delivery systems: recent developments and prospects. Journal of nanobiotechnology, 16(1), 1-33.

28. Płotka-Wasylka, J., Mohamed, H. M., Kurowska-Susdorf, A., Dewani, R., Fares, M. Y., \& Andruch, V. (2021). Green analytical chemistry as an integral part of sustainable education development. Current Opinion in Green and Sustainable Chemistry, 100508.

29. Rao, T. N. (2018). Validation of analytical methods. Calibration and Validation of Analytical Methods-A Sampling of Current Approaches.

30. Rasul Fallahi, M., \& Khayatian, G. (2017). Colourimetric Detection of $\mathrm{Cu}$ (II) in Water and Urine Samples Using 2, 2'-Thiodiacetic Acid Modified Silver Nanoparticles. Current Analytical Chemistry, 13(2), 167-173.

31. Shen X, Boswell CA, Wong EH, Weisman GR, Anderson CJ, Tomellini SA. Investigation of copper-azamacrocyclic complexes by high-performance liquid chromatography. Biomed Chromatogram. 2006 Jan;20(1):37-47. doi: 10.1002/bmc.525. PMID: 15954159.

32. Soetan, K. O., Olaiya, C. O., \& Oyewole, O. E. (2010). The importance of mineral elements for humans, domestic animals and plants-A review. African journal of food science, 4(5), 200-222.

Peer) An. Chem. reviewing PDF | (ACHEM-2021:08:65001:1:2:NEW 15 Jan 2022) 
33. Takele, A., Attaya, A. M. I. M., Hymete, A., \& Alula, M. T. (2017). High-Performance Liquid Chromatography (HPLC) Stability Indicating Method for the Determination of Bromazepam Via its Copper (II) Chelates. Open Pharmaceutical Sciences Journal, 4(1).

34. Turner, C. (2013). Sustainable analytical chemistry — more than just being green. Pure and Applied Chemistry, 85(12), 2217-2229.

35. Uddin, M. N., Samanidou, V. F., \& Papadoyannis, I. N. (2008). Development and related technologies, 31(9), 1258-1282.

36. USP 2019. $<1225>$ Validation of Compendial Procedures and $<621>$ Chromatography. Rockville, Rockville, MD: United States Pharmacopeia. new sorbent for solid-phase extraction of copper (II), and its determination by electrothermal AAS. Microchimica Acta, 181(9-10), 949-956.

38. Wolf, I. M. A., Diercks, B.-P., Gattkowski, E., Czarniak, F., Kempski, J., Werner, R., DNA-modified gold-nanoparticle aggregates as probes and click chemistry. Small, 6(5), 623-626. 
40. Zeng, L., Fang, Z., \& Wang, Y. (2018). Colorimetric Detection of Copper Ion Based on

396

Click Chemistry. Noble and Precious Metals: Properties, Nanoscale Effects and

397 Applications, 367. 


\section{Figure 1}

\section{Chemical structure of Cu-EDTA COMPLEX}

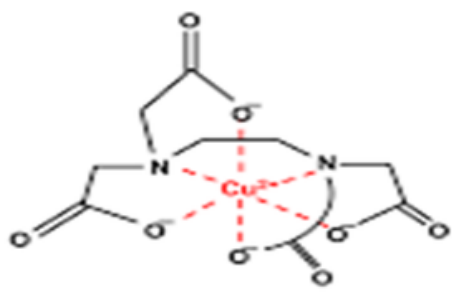

CUIII-EDTA 
Figure 2

TEM of Cu-Chitosan nanocomposite showed $24.71 \pm 1.68 \mathrm{~nm}$ with polydispersity index (Pdl):0.691 \pm 0.02 , sphere shape and no aggregation. 


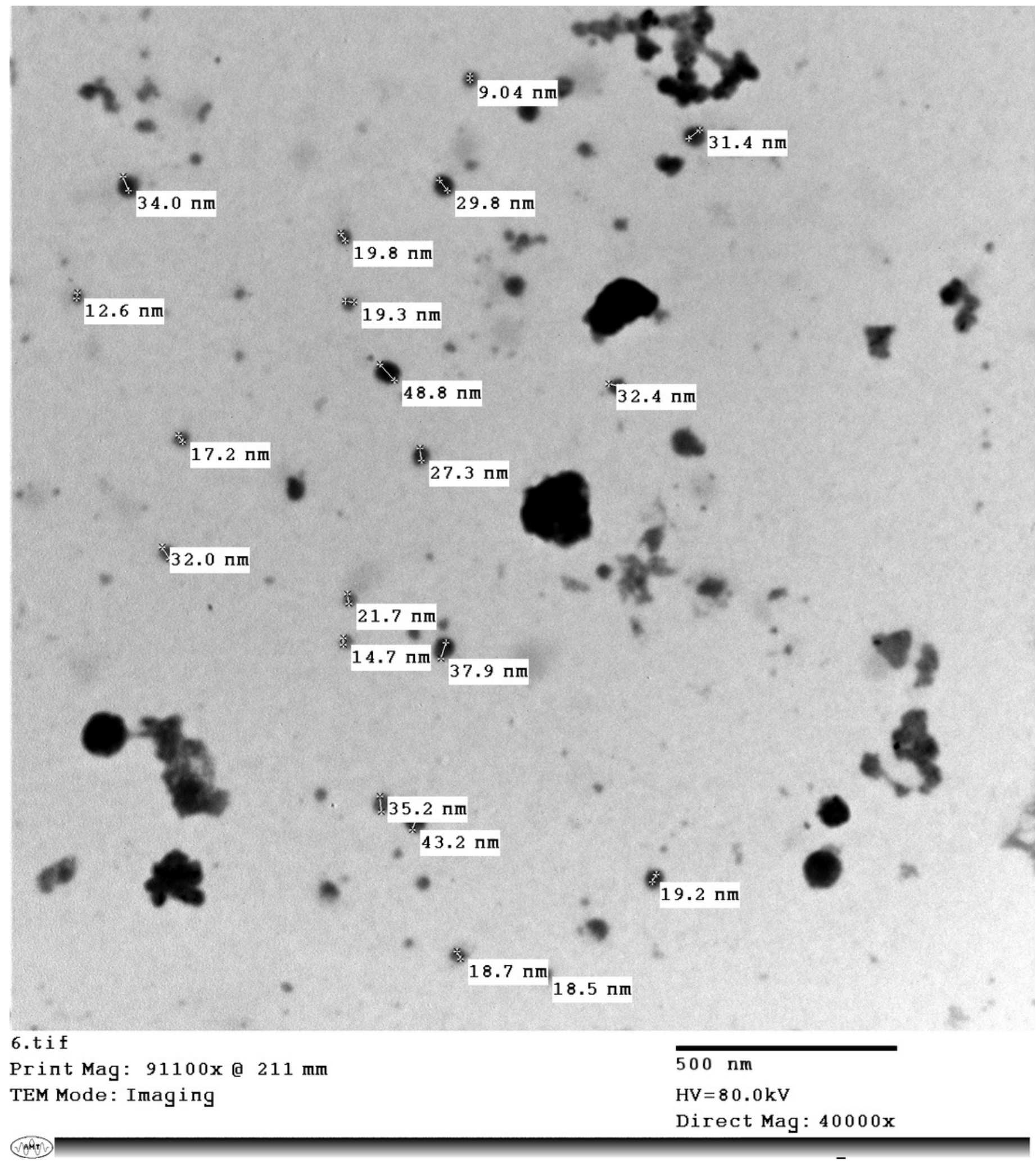


Figure 3

PDF file for Fig 3 with all its section (a,b,c and d)
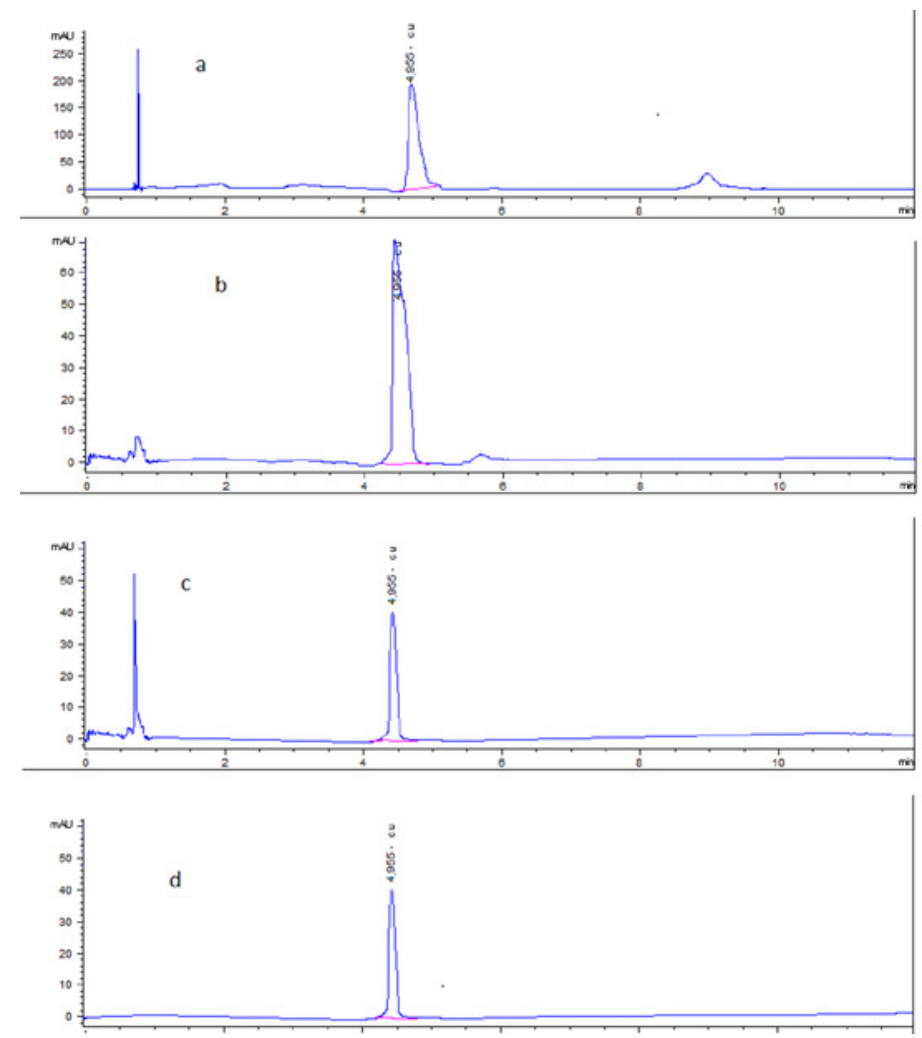


\section{Table 1 (on next page)}

Validation parameters results of $\mathrm{Cu}$ analytical method: 
1 Table (1): Validation parameters results of $\mathrm{Cu}$ analytical method:

\begin{tabular}{|l|l|l|l|l|l|}
\hline Parameter & Cu standard & Cu in & Cu in Liver & Cu in Muscle \\
\hline Range (ppm) & $0.05-20$ & \multicolumn{3}{|c|}{$0.1-15$} \\
\hline Regression & $\mathrm{y}=72.149 \mathrm{x}-$ & $\mathrm{y}=73.234 \mathrm{x}$ & $\mathrm{y}=73.263 \mathrm{x}+$ & $\mathrm{y}=75.323 \mathrm{x} \quad+$ \\
\hline equation & 0.104 & +0.128 & 0.3742 & 0.0594 \\
\hline Correlation & 0.9999 & 0.9999 & 0.9995 & 0.9998 \\
\hline Intraday precision & 0.696 & & & \\
\hline (RSD\%) & & 0.6 & 0.52 & 0.58 \\
\hline Inter-day precision & 1.04 & & & \\
\hline (RSD\%) & & 1.18 & 0.85 & 1.36 \\
\hline Recovery\% & $99.13-$ & $96.8-100.7$ & $99.98-104.75$ & $98.4-105.7$ \\
\hline Qccuracy & 101.01 & & & 0.023 \\
\hline DL (ppm) & $100.03 \pm 0.46$ & $99.4 \pm 1.4$ & $101.5 \pm 1.88$ & \\
\hline
\end{tabular}

2 
Table 2 (on next page)

SYSTEM SUITABILITY Test parameters of $\mathrm{Cu}$ at a concentration $(1 \mu \mathrm{g} / \mathrm{ml})$ 
1 Table (2): SST parameters of $\mathrm{Cu}$ at a concentration $(1 \mu \mathrm{g} / \mathrm{ml})$

\begin{tabular}{|l|l|l|l|l|l|}
\hline \multirow{2}{*}{ parameters } & $\begin{array}{l}\text { Cu } \\
\text { standard } \\
\text { insolvent }\end{array}$ & \multicolumn{5}{|c|}{ Serum } & Liver & Muscle & $\begin{array}{l}\text { Acceptance } \\
\text { criteria }\end{array}$ \\
\cline { 2 - 7 } & \multicolumn{5}{|c|}{ Mean \pm RSD } \\
\hline $\begin{array}{l}\text { Theoretical } \\
\text { plates (N) }\end{array}$ & $4033.3 \pm 0.3$ & $4421 \pm 0.3$ & $4231.2 \pm 0.106$ & $4264.3 \pm 0.92$ & $>2000$ \\
\hline $\begin{array}{l}\text { Retention } \\
\text { time (Rt) }\end{array}$ & $4.95 \pm 0.7$ & $4.953 \pm 0.02$ & $4.952 \pm 0.005$ & $4.955 \pm 0.58$ & RSD $<1.0 \%$ \\
\hline $\begin{array}{l}\text { Tailing } \\
\text { Factor (Tf) }\end{array}$ & $1.04 \pm 0.005$ & $1.01 \pm 0.1$ & $1.024 \pm 0.01$ & $1.16 \pm 0.3$ & $\leq 2.0$ \\
\hline Peak area & $72.9 \pm 0.81$ & $73.6 \pm 0.03$ & $73.9 \pm 0.008$ & $75.5 \pm 0.45$ & RSD $<1.0 \%$ \\
\hline $\begin{array}{l}\text { Symmetry } \\
\text { factor }\end{array}$ & $0.83 \pm 0.02$ & $0.92 \pm 0.02$ & $0.71 \pm 0.01$ & $0.68 \pm 0.3$ & $\leq 1.0$ \\
\hline
\end{tabular}

2 


\section{Table 3(on next page)}

Pharmaceutical formulations analysis 
1 Table (3): pharmaceutical formulations analysis

\begin{tabular}{|c|c|c|c|c|c|c|}
\hline Analyte & $\begin{array}{l}\text { Products } \\
\text { Name }\end{array}$ & $\begin{array}{l}\text { Added } \\
(50 \mathrm{ng} / \mathrm{mL}) / 3 \\
\text { levels }\end{array}$ & $\begin{array}{l}\text { Founded } \\
\operatorname{mean} \pm \text { SD }\end{array}$ & RSD\% & Recovery\% & $\begin{array}{c}\text { Accuracy } \pm \\
\text { SD }\end{array}$ \\
\hline Copper $(\mathrm{Cu})$ & $\begin{array}{l}\text { Clo-Fix } \\
(25 \mathrm{gm} / \mathrm{L})\end{array}$ & $\begin{array}{l}5 \mu \mathrm{g} / \mathrm{mL} \\
10 \mu \mathrm{g} / \mathrm{mL} \\
15 \mu \mathrm{g} / \mathrm{mL}\end{array}$ & $\begin{array}{l}5.045 \pm 0.005 \\
10.06 \pm 0.008 \\
15.038 \pm 0.02\end{array}$ & $\begin{array}{l}0.11 \\
0.08 \\
0.18\end{array}$ & $\begin{array}{l}100.9 \\
100.6 \\
100.3\end{array}$ & $100.58 \pm 0.3$ \\
\hline & $\begin{array}{l}\text { Meracid } \\
(10 \mathrm{mg} / \mathrm{L})\end{array}$ & $\begin{array}{l}5 \mu \mathrm{g} / \mathrm{mL} \\
10 \mu \mathrm{g} / \mathrm{mL} \\
15 \mu \mathrm{g} / \mathrm{mL}\end{array}$ & $\begin{array}{l}5.05 \pm 0.01 \\
10.05 \pm 0.001 \\
15.05 \pm 0.003\end{array}$ & $\begin{array}{l}0.2 \\
0.01 \\
0.02\end{array}$ & $\begin{array}{l}101.1 \\
100.5 \\
100.3\end{array}$ & $100.63 \pm 0.4$ \\
\hline $\begin{array}{l}\mathrm{Cu} \\
\text { nanoparticle } \\
\text { (CuNPs) }\end{array}$ & $\begin{array}{l}\text { CuCNPs } \\
\text { Preparation } \\
(3 \mathrm{~g} / \mathrm{L})\end{array}$ & $\begin{array}{l}0.5 \mu \mathrm{g} / \mathrm{mL} \\
1 \mu \mathrm{g} / \mathrm{mL} \\
1.5 \mu \mathrm{g} / \mathrm{mL}\end{array}$ & $\begin{array}{l}0.55 \pm 0.01 \\
1.05 \pm 0.002 \\
1.55 \pm 0.002\end{array}$ & $\begin{array}{l}1.1 \\
0.2 \\
0.1\end{array}$ & $\begin{array}{l}109.9 \\
105.4 \\
103.4\end{array}$ & $106.2 \pm 2.9$ \\
\hline
\end{tabular}


Table 4 (on next page)

Comparison of the results obtained by the developed HPLC method and ICP-MS for the determination of copper in spiked biological samples, pharmaceutical product and CuCNPs composite preparation: 
1

2

3

4

5

6

7 Table (4): Comparison of the results obtained by the developed HPLC method and ICP-MS for 8 the determination of copper in spiked biological samples, pharmaceutical product and CuCNPs 9 composite preparation:

10

\begin{tabular}{|l|l|l|l|l|}
\hline Sample & $\begin{array}{l}\text { Spiked } \\
(\mathbf{P P M})\end{array}$ & HPLC method & Recovery (\%) & ICP/MS (PPM) \\
\hline \multirow{2}{*}{ Serum } & 0.5 & $0.503 \pm 0.002$ & 100.7 & $0.51 \pm 0.001$ \\
\cline { 2 - 5 } & 1 & $1.029 \pm 0.005$ & 102.9 & $1.03 \pm 0.004$ \\
\hline \multirow{3}{*}{ Liver } & 0.5 & $0.498 \pm 0.006$ & 99.7 & $0.501 \pm 0.002$ \\
\cline { 2 - 5 } & 1 & $1.026 \pm 0.003$ & 102.6 & $1.022 \pm 0.005$ \\
\hline \multirow{2}{*}{ Muscle } & 0.5 & $0.502 \pm 0.002$ & 100.5 & $0.499 \pm 0.01$ \\
\cline { 2 - 5 } & 1 & $1.017 \pm 0.01$ & 101.8 & $1.012 \pm 0.01$ \\
\hline \multirow{2}{*}{ CuCNPs (0.5ppm) } & 0.05 & $0.54 \pm 0.03$ & 98.2 & $0.55 \pm 0.1$ \\
\cline { 2 - 5 } & 0.1 & $0.603 \pm 0.2$ & 100.5 & $0.599 \pm 0.01$ \\
\cline { 2 - 5 } & 0.05 & $0.55 \pm 0.01$ & 109.9 & $0.54 \pm 0.1$ \\
\hline
\end{tabular}

